\title{
Bio-Based Graphene Sheet/Copolymer Composite as Supporting Material for Nanocatalysts towards Electrochemical Studies and Direct Alkaline Alcohol Fuel Cells
}

\author{
V. Selvaraj $\mathbb{D}^{1},{ }^{1}$ R. ThamilMagal $\mathbb{D},{ }^{1,2}$ V. Andal $\mathbb{D},{ }^{3}$ K. Arunkumar, ${ }^{1}$ and Sivaraj Murugan $\mathbb{D}^{4}$ \\ ${ }^{1}$ Nanotech Research Lab, Department of Chemistry, University College of Engineering, Kakuppam, Villupuram, \\ 605103 Tamilnadu, India \\ ${ }^{2}$ Department of Chemistry, University College of Engineering, Panikkankuppam, Panruti, Tamilnadu, India \\ ${ }^{3}$ Department of Chemistry, KCG College, Karapakkam, Tamil Nadu, Chennai, Tamilnadu, India \\ ${ }^{4}$ Department of Mechanical Engineering, Institute of Technology, Hawassa University, Hawassa, Ethiopia
}

Correspondence should be addressed to V. Selvaraj; vaithilingamselvaraj@gmail.com and Sivaraj Murugan; msivaraj2014@gmail.com

Received 13 August 2021; Revised 14 October 2021; Accepted 9 December 2021; Published 6 January 2022

Academic Editor: Raul Arenal

Copyright @ 2022 V. Selvaraj et al. This is an open access article distributed under the Creative Commons Attribution License, which permits unrestricted use, distribution, and reproduction in any medium, provided the original work is properly cited.

\begin{abstract}
In this work, graphene carbon sheets (BGS) were prepared from writing paper and lemon peel, and its polymer composite has a higher surface area compared with the existing Vulcan carbon. Further, the use of lead as a promoter for the oxidation of alcohol and $\mathrm{CO}$ on platinum-supported poly(amine-terminated cyclophosphazene-co-cyclophosphazene)-biobased graphene sheet (Poly(AFCP-co-CP)-BGS) composite was demonstrated. The size, phase morphology, and distribution of metal nanoparticles on Poly(AFCP-co-CP)-BGS composite as well as the formation of composite based catalysts were confirmed from TEM, XRD, and FTIR studies. The catalytic activity and stability of the prepared catalysts were tested and compared to methanol, ethylene glycol, glycerol, and $\mathrm{CO}$ in $0.5 \mathrm{M} \mathrm{KOH}$ solution. The results conclude that the lead-doped Pt/Poly(AFCP-co-CP)-BGS catalyst shows higher oxidation current with respect to onset potential and lower $I_{\mathrm{f}} / I_{\mathrm{r}}$ ratio for alcohol as well as CO oxidation. In addition, $\mathrm{Pt}-\mathrm{Pb} / \mathrm{Poly}(\mathrm{AFCP}-\mathrm{co}-\mathrm{CP})$-BGS catalyst was checked for direct alkaline fuel cells and proved as a potent anode catalyst in alkaline medium for real-time fuel battery applications. In addition, Poly(AFCP-co-CP)-BGS composite also promotes the catalytic reaction compared to Poly(AFCP-co-CP) and BGS supports as noticed from methanol oxidation in alkaline medium. The surface area of the prepared supporting material is $750.72 \mathrm{~m}^{2} \mathrm{~g}^{-1}$, which is higher than the activated carbon $\left(250.12 \mathrm{~m}^{2} \mathrm{~g}^{-1}\right)$. So, the prepared Poly(AFCP-co-CP)-BGS composite is a potent support for metal deposition, electrooxidation, and single stack fuel cell constructions.
\end{abstract}

\section{Introduction}

The increasing population, development in technology, modern culture, and sophisticated modern appliances require large quantity of power and increase the demand of power day by day. Almost 70 to $80 \%$ demand of power is being fulfilled by fossil fuel. However, the depletion of fossil fuel, scarcity, and its high cost are tempting the scientists to search some new energy resources. In this aspect, alkaline direct alcohol fuel cells (ADAFCs) have received much attention as they have more advantageous properties like improved methanol oxidation kinetics in alkaline than that of the acidic media. Further, they have low permeability of alcohol from anode to cathode and low-cost membranes [1,2].

The developments of anode and cathode catalysts with better bustle as well as with decreased poison effects are the emerging area of research. In most of the cases, platinum and platinum-based nanoalloys (e.g., Pt-Ru, Pt-Au, Pt-Sn, and Pt-Pd) are frequently used as electrocatalysts in ADMFCs because of their high activities and stabilities [3-8]. But the high cost, scarcity, and poisonous effect of platinum catalyst limit its usefulness in commercial applications. In order to 
decrease the platinum loading and to increase electrochemical performance for alcohol and $\mathrm{CO}$ oxidation, the studies are being performed using non-platinum-based catalysts and platinum loaded with appropriate support materials $[9,10]$. The catalyst's activity and stability of alcohol oxidation in alkaline medium depend not only on the presence of metal nanoparticles but also on the properties of support material and interactions between the metal particles and support materials. Generally, conductive polymers [11]; carbon-based materials like graphene, carbon nanotubes, carbon fibers, and mesoporous carbon [12-15]; metal sulfides [16]; and zeolites [17] are used as catalyst supports for various applications.

The mesoporous carbon, a relatively new type of carbonbased material has become popular as an electrocatalyst support because of its large surface area, exceptional thermal and chemical durability, and stupendous electrical conductivity $[18,19]$. Various nitrogen-doped carbon materials have been prepared recently as supports to promote the electrocatalytic activities of platinum-based catalysts for alcohol oxidation reactions (AOR) and oxygen reduction reaction [20-25] to be used in the applications of fuel cells. Recently, biobased carbons are used in various applications such as polymer composites [26-28], dye degradations, electromagnetic studies [29, $30]$, 3D printing [31], sensors, and electrocatalysts [32, 33]. Further, preparation, morphology, and electrochemical characterization of electrodeposited nanocrystalline Ni-Co [34], $\mathrm{Au} / \mathrm{Pt}$ nanoanode [35], and ultrafine PtPd bimetallic nanoparticles [36] are studied for alcohol fuel cell applications. Generally, it has been found that the most frequently used methods for the preparation of nitrogen-doped carbon-based nanomaterials are pyrolysis and chemical vapour deposition (CVD). Alternatively, the nitrogen-containing pioneers like poly(indole), poly(pyrrole), and poly(aniline) have also been doped with carbon based materials via in situ polymerization procedure [37-41]. Advantages like uncomplicated preparation technique, producing more anchoring sites, and resulting improved conductivity can be derived from this procedure.

Having these points in mind, the present work has been initiated to prepare a composite-based hybrid supporting material containing both phosphorous and nitrogen along with biobased graphene carbon sheet. Moreover, lead nanoparticles have been doped on Pt/Poly(AFCP-Co-CP)-BGS material to promote the catalytic activity of alcohol and $\mathrm{CO}$ oxidation in alkaline medium.

Typically, poly(amine-terminated cyclophosphazene-cocyclophosphazene)-biobased graphene carbon sheet (Poly(AFCP-co-CP)-BGS) composite was prepared through an in situ sonochemical method. To check the performance and promotion of catalytic activity of the prepared Poly(AFCPco-CP)-BG composite, platinum nanocatalyst was coated on BGS, Poly(AFCP-co-CP), and Poly(AFCP-co-CP)-BGS. Various analytical methods such as X-ray diffraction (XRD), energy dispersive X-ray analysis (EDX), transmission emission spectroscopy (TEM), and Fourier Transform Infrared Spectroscopy (FTIR) were employed to characterized the metal nanoparticle-deposited Poly(AFCP-co-CP)-BGS composite catalysts. It was concluded from the electrochemical studies that the lead-doped Pt/Poly(AFCP-co-CP)-BG composite promotes both alcohol and $\mathrm{CO}$ oxidation reactions.
To add further, Poly(AFCP-co-CP)-BGS composite also promotes the alcohol oxidation when compared with Poly(AFCP-co-CP) and BGS supports. It is suggested by the above results that both doping of lead as second metal and Poly(AFCP-co-CP)-BGS composite as support material promote the catalytic activity for alcohol and $\mathrm{CO}$ oxidation in fuel cell applications.

\section{Materials and Methods}

2.1. Materials. Hexachloroplatinic acid hexahydrate $\left(\mathrm{H}_{2} \mathrm{PtCl}_{6} \cdot 6 \mathrm{H}_{2} \mathrm{O}\right)$, lead(II)acetate trihydrate $\left(\mathrm{Pb}(\mathrm{OAc})_{2} \cdot 3 \mathrm{H}_{2} \mathrm{O}\right)$, formaldehyde, resorcinol, $\mathrm{N}, \mathrm{N}^{\prime}$ dimethyl sulfoxide, $\mathrm{HCl}$, $\mathrm{H}_{2} \mathrm{SO}_{4}$, ethanol, methanol, ethylene glycol, glycerol, sodium hydroxide $(\mathrm{NaOH})$, and triethylamine were purchased from SRL Chemicals, India. Hexachlorocyclotriphosphazene was purchased from Alfa Aesar, India. All the solvents were analytical grade and used as obtained from the chemical industries.

2.2. Preparation of Biobased Graphene Carbon Sheets. Using a modified reported procedure [42], biobased graphene carbon sheets (BGS) were prepared. BGS was prepared via a hydrothermal method by carbonization of waste materials such as waste writing paper (60\%) and lemon peel (30 wt.\%) using $50 \%$ dilute $\mathrm{H}_{2} \mathrm{SO}_{4}(170 \mathrm{~mL})$ at $448 \mathrm{~K}$. Typically, $6 \mathrm{gm}$ waste writing paper and $4 \mathrm{~g}$ of waste lemon peel materials was heated at $448 \mathrm{~K}$ with $50 \%$ dilute $\mathrm{H}_{2} \mathrm{SO}_{4}(170 \mathrm{~mL})$ for 24 hours in an autoclave. When the hydrothermal reaction was completed, the autoclave was cooled and resulted product was filtered, washed with distilled water to remove excess acid. The washing was repeated until the filtrate became neutral. Finally, the resulted product was redispersed in the double distilled water and centrifuged to remove the ash material floating on the water if formed during the hydrothermal process. Finally, the filtered product was dried in a hot air oven. The dried product was ground into powder, and the resulted fine powder was immersed in $\mathrm{KOH}$ solution, which was then heated at $1093 \mathrm{~K}$ for $3 \mathrm{~h}$ in an inert atmosphere. The resultant biobased graphene powder was also washed with $20 \% \mathrm{HCl}(v / v)$ to remove the inorganic impurities and then washed down with distilled water until the washed liquid became neutral $\mathrm{pH}$. The biobased graphene carbon powder was dried in an oven at $70^{\circ} \mathrm{C}$.

2.3. Preparation of Amine-Terminated Cyclotriphosphazene. The amine-terminated cyclotriphosphazene monomer was prepared as explained in our previous report $[43,44]$. For this preparation, 4 -acetamido phenol $(15.65 \mathrm{~g}, 0.1035 \mathrm{~mol})$ and $\mathrm{K}_{2} \mathrm{CO}_{3}(21.09 \mathrm{~g}, 0.15824 \mathrm{~mol})$ were dispersed in dry acetone $(200 \mathrm{~mL})$ and effectively stirred at an ambient temperature for 45 minutes. To this mixture, hexachlorocyclotriphosphazene $(5 \mathrm{~g}, 0.0143 \mathrm{~mol})$ was added and refluxed at $60-65^{\circ} \mathrm{C}$ for 4 days. The product obtained as the result of the chemical reaction was cooled naturally to room temperature and filtered. The impure resulted sample (CPAC) was further purified using hexane and dried at $60^{\circ} \mathrm{C}$ for $3 \mathrm{~h}$. It gave a yield of $63.8 \%$ and m.p. $253-256^{\circ} \mathrm{C}$. The reaction mixture of hexa(acetamidophenyl)cyclotriphosphazene (9.0 g), methanol $(180 \mathrm{~mL})$, and sulfuric acid $(108 \mathrm{~mL})$ was taken in the 
round bottom flask and refluxed for $4 \mathrm{~h}$ at $80-85^{\circ} \mathrm{C}$. Then, the resultant reaction mixture was cooled to $25^{\circ} \mathrm{C}$ and then poured in to ice-cold water. To this, aqueous ammonia solution was added drop by drop until to reach $\mathrm{pH}=8$. The resulted solid product was filtered, washed with water, and dried at $60^{\circ} \mathrm{C}$ for $48 \mathrm{~h}$.

\subsection{Preparation of Poly(AFCP-co-CP)-BGS Composite.} Poly(amine-terminated cyclophosphazene-co-cyclophosphazene)-biobased graphene carbon sheet (Poly(AFCP-coCP)-BGS) composite-based support material was prepared using the modified procedure reported elsewhere [45]. For this copolymer-biobased graphene carbon sheet composite preparation, $58 \mathrm{mg}$ of amine-terminated cyclophosphazene, and $116 \mathrm{mg}$ cyclophosphazene were dissolved in $100 \mathrm{~mL}$ of $\mathrm{N}, \mathrm{N}^{\prime}$-dimethyl sulfoxide (DMSO) solvent. With this reaction mixture, $10 \mathrm{mg}$ of biobased graphene carbon sheet was added and dispersed utilizing ultrasonicator for 10 minutes. Finally, $4 \mathrm{~mL}$ of triethylamine was added to the above reaction mixture to start polymerization over graphene carbon sheet carbon, and the reaction was continued for another 12 hours under sonication $(100 \mathrm{~W}, 40 \mathrm{kHz})$ at $30^{\circ} \mathrm{C}$. The final resulted product was centrifuged, and the obtained Poly(AFCP-Co-CP)-BGS composite was washed with ethanol followed by double distilled water and then dried at $50-60^{\circ} \mathrm{C}$ for 12 hours.

\subsection{Preparation of $\mathrm{Pt}$ and $\mathrm{Pt}-\mathrm{Pb}$ Nanoparticle-Deposited} Poly(AFCP-co-CP)-Biobased Graphene Carbon Sheet Composites. Platinum-lead nanoparticle-deposited Poly(AFCP-co-CP)-BGS catalyst (Pt-Pb/Poly(AFCP-co-CP)BGS) was prepared by the formaldehyde reduction method [45]. For catalyst preparation, $70 \mathrm{mg}$ Poly(AFCP-co-CP)BGS composite was dispersed in $10 \mathrm{~mL}$ distilled water using an ultrasonic process for 30 minutes. $54 \mathrm{mg} \mathrm{H}_{2} \mathrm{PtCl}_{6} \cdot 6 \mathrm{H}_{2} \mathrm{O}$ and $38 \mathrm{mg} \mathrm{Pb}(\mathrm{OAc})_{2} 3 \mathrm{H}_{2} \mathrm{O}$ dissolved in $40 \mathrm{~mL}$ of distilled water as a bimetallic catalyst precursor solution were added to the above suspension in drop by drop method and then $\mathrm{pH}$ was adjusted to 11 with $2.5 \mathrm{M} \mathrm{NaOH}$ solution. Stirring after about 30 minutes, $4 \mathrm{~mL}$ formaldehyde (37\%) was added to the above solution at $85^{\circ} \mathrm{C}$. The reduction reaction was continued for another five hours to dope platinum-lead nanoparticles on Poly(AFCP-co-CP)-BGS composite through an in situ codeposition method. The resulted Pt-Pb/Poly(AFCP-coCP)-BGS solid was filtered, washed with distilled water, and then dried at $60^{\circ} \mathrm{C}$ for $8 \mathrm{hrs}$. Similarly, the platinum nanoparticles were deposited on Poly(AFCP-co-CP)-BGS composite $(30 \mathrm{mg})$ by the $\mathrm{HCHO}(2 \mathrm{~mL})$ reduction method with $54 \mathrm{mg}$ of $\mathrm{H}_{2} \mathrm{PtCl}_{6} \cdot 6 \mathrm{H}_{2} \mathrm{O}$ precursor to form $\mathrm{Pt} / \mathrm{Poly}(\mathrm{AFCP}-\mathrm{co}-\mathrm{CP})$ BGS catalyst by following same experimental procedure. To compare the efficiency of Poly(AFCP-co-CP)-BGS composite, the platinum nanoparticles were also deposited on Poly(AFCP-co-CP), biobased graphene carbon sheet (BGS) by following same experimental condition.

2.6. Fabrication of Working Electrodes. For the fabrication of working electrode, $5 \mathrm{mg}$ of $\mathrm{Pt}-\mathrm{Pb} / \mathrm{Poly}(\mathrm{AFCP}-\mathrm{co}-\mathrm{CP})-\mathrm{BGS}$ catalyst was dispersed in a mixture of $100 \mu \mathrm{L}$ of $0.05 \%$ of Nafion solution and isopropanol $(1: 1)$ solution. A measured volume of $25 \mu \mathrm{L}$ of this suspension was dropped on the top surface of the graphite electrode by using micropipette. The modified electrodes were used as working electrode for the electrooxidation of alcohol in alkaline medium. Similarly, the other catalysts Pt/Poly(AFCP-co-CP)-BGS, Pt/ Poly(AFCP-co-CP), and Pt/BGS were also prepared by following the same procedure.

2.7. Characterization Techniques. To record the FT-IR spectra of the prepared samples, Perkin Elmer 6X FT-IR spectrometer was used. About $100 \mathrm{mg}$ of optical grade $\mathrm{KBr}$ was grounded with sufficient quantity of the sample for making KBr pellets. Wide-angle X-ray spectra of the prepared samples were obtained using a Rich Seifert (Model 3000) diffractometer with CuKI radiation $(\theta=0.15418 \mathrm{~nm})$, and the spectra were recorded from $0^{\circ}$ to $80^{\circ}$ at $2 \theta$ value. To characterize the size and phase morphology of the prepared catalyst, the AJEOLJEM-3010 analytical transmission electron microscope was used, which was operated at $300 \mathrm{kV}$ with a measured point-to-point resolution of $0.23 \mathrm{~nm}$. The HRTEM samples were prepared by dispersing the prepared catalyst in ethanol mounted on carbon coated copper grids and dried for $24 \mathrm{~h}$ at $25^{\circ} \mathrm{C}$. A standard three-electrode glass cell equipped with prepared catalyst coated on graphite electrode was considered working, saturated calomel electrode was taken as reference, and platinum wire was used as counter electrode for the present investigation. Further, the electrocatalytic activity of alcohol oxidation was investigated in $0.5 \mathrm{M} \mathrm{KOH}$ and $0.5 \mathrm{M}$ alcohol solution with a potential window of -1.0 to $0.3 \mathrm{~V}$.

\section{Results and Discussions}

3.1. Fourier Transform Infrared Analysis of Poly(AFCP-co$C P)$ and Poly(AFCP-co-CP)-BGS Composite. Figure 1 shows the FT-IR spectra of Poly(AFCP-co-CP) and Poly(AFCPco-CP)-BGS composite. The two bands observed at 3438 and $3338 \mathrm{~cm}^{-1}$ are corresponding to $-\mathrm{NH}$ stretching vibrations; in fact, they also ascertain the presence of AFCP material in Poly(AFCP-co-CP) copolymer (Figure 1). The peak noticed at $3043 \mathrm{~cm}^{-1}$ is assigned to ring $\mathrm{C}-\mathrm{H}$ stretching vibration. The aromatic $\mathrm{C}-\mathrm{C}$ stretching vibrations appear at 1507 and $1621 \mathrm{~cm}^{-1}$. The typical stretching vibrations of P-O-Ph, P-N-P, and P-O-C appear at 1256, 1178, and $952 \mathrm{~cm}^{-1}$, respectively. The aromatic $\mathrm{C}-\mathrm{H}$ bending vibrations are visualized at 832 and $695 \mathrm{~cm}^{-1}$.

Peaks with similar patterns are noticed for poly(amineterminated cyclophosphazene-co-cyclophosphazene)-graphene carbon sheet composite. Further, it is noticed with a small shift in the wave number, which is due to the coating behavior of poly(amine-terminated cyclophosphazene-cocyclophosphazene) copolymer on a biobased graphene carbon sheet.

3.2. BET Surface Analysis of the Prepared Poly(AFCP-co-CP)$B G S$ Supporting Materials. The surface area of biobased graphene carbon sheet-conductive copolymer (Poly(AFCPco-CP)-BGS) was analyzed using the BET method. Figure 2 shows the $\mathrm{N}_{2}$ adsorption-desorption measurements of the newly prepared biobased graphene carbon sheet-conductive 


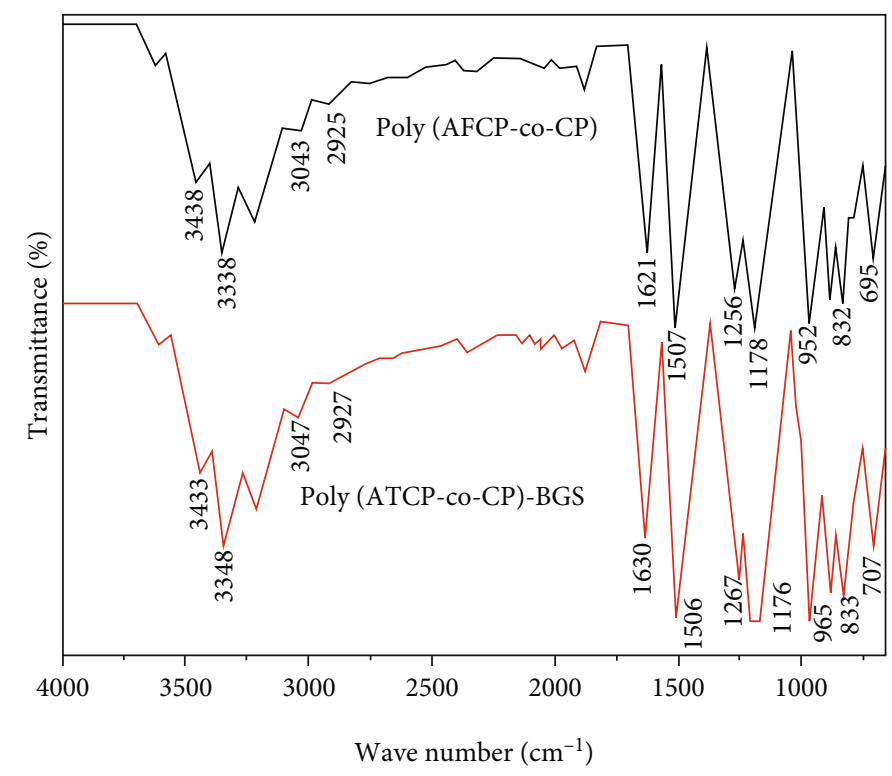

Figure 1: FTIR spectra of Poly(AFCP-co-CP) copolymer and Poly(AFCP-co-CP)-BGS composite.

copolymer composite. The adsorption-desorption curve in Figure 2 reveals a linear increase at low $P / P_{0}$ below 0.4 . A hysteresis loop between $P / P O=0.5-0.9$ is observed, which indicates the presence of graphene carbon sheet. The specific surface area of the BGS is determined to be $750.72 \mathrm{~m}^{2} \mathrm{~g}^{-1}$ with a total pore volume of $0.318 \mathrm{~cm}^{3} \mathrm{~g}^{-1}$ and an average pore diameter of $6.6592 \mathrm{~nm}$.

According to a previous report [42], the specific surface area of Vulcan carbon black was determined to be $250.12 \mathrm{~m}^{2} \mathrm{~g}^{-1}$ with a total pore volume of $2.31 \mathrm{~cm}^{3} \mathrm{~g}^{-1}$. The Poly(AFCP-co-CP)-BGS composite surface area was about three times larger that of the Vulcan carbon black. The high surface area determined by the BET method is correlated with improved catalytic activity. Therefore, the present study predicts that the catalytic activity of biobased Poly(AFCPco-CP)-BGS composite should be superior to that of the Vulcan carbon blacks.

3.3. X-Ray Diffraction Analysis. XRD pattern of platinum nanoparticle-deposited Poly(AFCP-co-CP)-BGS composite shows three diffraction peaks at $2 \theta$ values of $39.25^{\circ}, 45.25^{\circ}$, and $66.84^{\circ}$ (Figure 3), which are matching to (111), (200), and (220) faces of the $f c c$ platinum. The same type of pattern is noticed for Pt-Pb bimetallic nanoparticle-deposited Poly(AFCP-co-CP)-BGS composite with the miniature shift to lower $2 \theta$ values with respect to $\mathrm{Pt} / \mathrm{Poly}(\mathrm{AFCP}-\mathrm{co}-\mathrm{CP})-\mathrm{BGS}$ composite. This is the atomic level displacement formation of bimetal $\mathrm{Pt}-\mathrm{Pb}$ catalyst, and no other diffraction peaks that correspond to lead oxide/hydroxide are observed. Thus, $\mathrm{XRD}$ results obviously demonstrate that $\mathrm{Pt}-\mathrm{Pb}$ nanoparticles are bimetallic and displacement in the crystalline structure is in the atomic level $[43,44]$.

3.4. Transmission Electron Microscope Analysis. TEM images of the platinum and platinum-lead nanoparticle-doped Poly(AFCP-co-CP)-BGS composites are shown in Figure 4. The prepared metal ( $\mathrm{Pt}$ and $\mathrm{Pt}-\mathrm{Pb}$ ) nanoparticles have been well deposited as black dots on Poly(AFCP-co-CP)-BGS composite sheet without any aggregations. The presence of these homogeneously distributed nitrogen species on the surfaces of Poly(AFCP-co-CP)-BGS composite sheet could effectively provide good anchoring sites for the deposition of metal nanoparticles during the reduction process of their respective precursor metal salts, which favors small metal (Pt and $\mathrm{Pt}-\mathrm{Pb}$ ) nanoparticle formation with enhanced active surface area.

3.5. Cyclic Voltammetry Analysis. Cyclic voltammograms of platinum and platinum-lead nanoparticle-deposited Poly(AFCP-co-CP)-BGS electrodes have been carried out in $0.5 \mathrm{M} \mathrm{KOH}, 0.5 \mathrm{M} \mathrm{KOH}+0.5 \mathrm{M}$ methanol, $0.5 \mathrm{M} \mathrm{KOH}$ $+0.5 \mathrm{M}$ ethylene glycol, and $0.5 \mathrm{M} \mathrm{KOH}+0.5$ glycerol solution at $50 \mathrm{mV} \mathrm{s}^{-1}$ (Figure 5).

From Figure 5(a), no change in the electroactive surface area of both Pt/Poly(AFCP-co-CP)-BGS and Pt-Pb/ Poly(AFCP-co-CP)-BGS catalysts is noticed and they are nearly the same. Before entering into the detailed studies, it is essential to prove that Poly(AFCP-co-CP)-BGS support is better than the other support Poly(AFCP-co-CP) and BGS. To check the performances of the prepared Poly(AFCP-co-CP)-BGS support, platinum nanoparticledeposited Poly(AFCP-co-CP)-BGS, Poly(AFCP-co-CP), and BGS catalysts have been subjected to the electrooxidation of methanol in alkaline medium.

Figure 5(b) shows the cyclic voltammograms of methanol in alkaline medium on platinum-deposited Poly(AFCP-coCP)-BGS, Poly(AFCP-co-CP) and BGS catalysts. From Figure 5(b), it is found that the methanol oxidation peak current of $\mathrm{Pt} / \mathrm{Poly}$ (AFCP-co-CP)-BGS catalyst is higher than that of the Pt/Poly(AFCP-co-CP) and Pt/BGS (Table 1). In addition, the Pt/Poly(AFCP-co-CP)-BGS exhibits lower onset potential than the Pt/Poly(AFCP-Co-CP) and Pt/BGS catalysts. It has been concluded from this result that the Poly(AFCP-CO-CP)-BGS is a potent support than the Poly(AFCPco-CP) and BGS. It is because of the integrated properties 


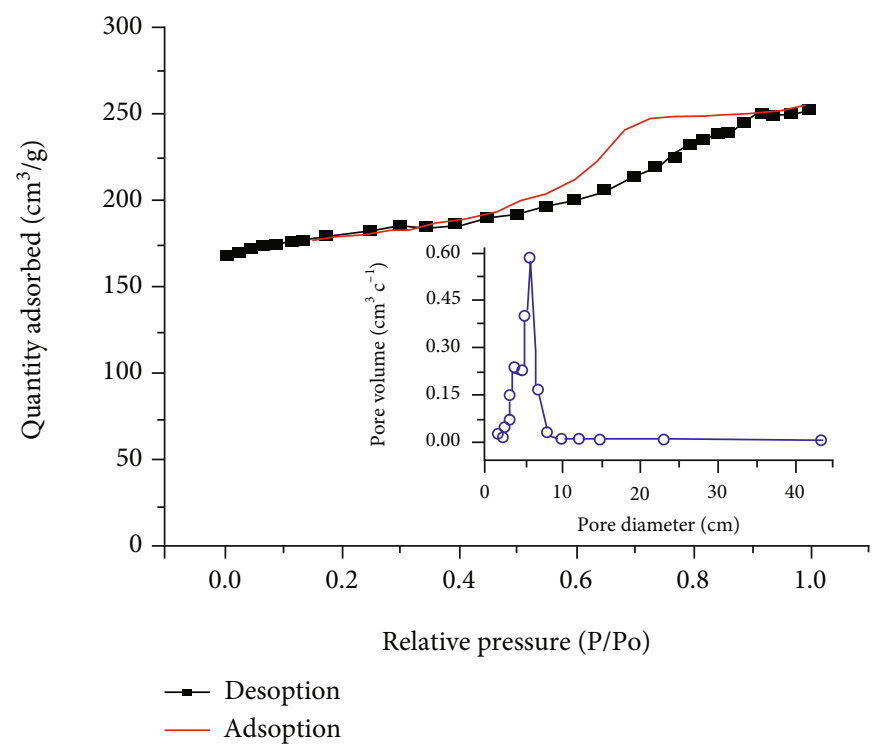

FIgURe 2: BET surface analysis of Poly(AFCP-co-CP)-BGS composite through nitrogen adsorption-desorption curves.

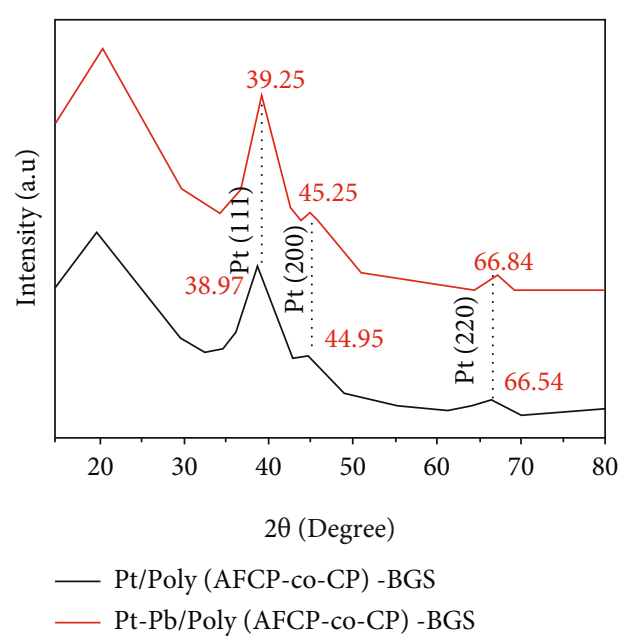

Figure 3: XRD patterns of Pt- and Pt-Pb-deposited Poly(AFCP-coCP)-BGS composites.

resulted from noncovalent interaction between the BGS and Poly(AFCP-co-CP) in Poly(AFCP-co-CP)-BGS composite and the multifunctional groups $(-\mathrm{NH},-\mathrm{O}$, and $-\mathrm{P})$ present on Poly(AFCP-co-CP)-BGS acts as a better anchoring site for the uniform distribution of metal nanoparticles.

To promote the catalytic activity and to decrease the onset potential, the second metal lead $(\mathrm{Pb})$ is added with Pt/Poly(AFCP-co-CP)-BGS catalyst. Hence, the prepared bimetal $\mathrm{Pt}-\mathrm{Pb} / \mathrm{Poly}(\mathrm{AFCP}-\mathrm{co}-\mathrm{CP})$-BGS catalyst is analyzed for electrooxidation of methanol (Figure 5(b)). It has been noticed from the cyclic voltammetry results of lead particle-doped Pt/Poly(AFCP-co-CP)-BGS catalyst that both improved oxidation peak current and reduced onset potential values exist. The current density and onset potential of the prepared catalysts are given in Table 1. The improved performance of $\mathrm{Pt}-\mathrm{Pb} / \mathrm{Poly}(\mathrm{AFCP}-\mathrm{co}-\mathrm{PC})-\mathrm{BGS}$ catalyst is because of the bifunctional mechanism of metal catalyst, electronic effect, and competitive adsorption of $\mathrm{OH}^{-}$on lead nanoparticles surface. Further, $\mathrm{Pb}-\mathrm{OH}$ is easily available near $\mathrm{Pt}-\mathrm{CO}_{\mathrm{ads}} / \mathrm{Pt}-\mathrm{OOCH}$ rather than $\mathrm{Pt}-\mathrm{OH}$, which can oxidize $\mathrm{CO}$ poison, $\mathrm{HCOO}^{-}$, etc., at lower potential range or level and results in more platinum free active surface for further adsorption of alcohol and oxidation.

So, this work has been extended to the electrooxidation of ethylene glycol and glycerol in an alkaline medium on the prepared Pt/Poly(AFCP-co-CP)-BGS and Pt-Pb/Poly(AFCP-co-CP)-BGS catalysts (Figures 5(c) and 5(d)). The electrochemical results confirm that Pt-Pb/Poly(AFCP-co$\mathrm{CP}$ )-BGS catalyst exhibits higher oxidation current and lower onset potential for both ethylene glycol and glycerol in alkaline medium compared to Pt/Poly(AFCP-co-CP)BGS catalyst (Table 1). Moreover, the oxidation current observed for ethylene glycol is higher than that of the oxidation current of methanol and glycerol. From the cyclic voltammetry analysis results, it has been concluded that the prepared Poly(AFCP-co-CP)-BGS composite is a good supporting material for metal catalysts.

In addition, the prepared $\mathrm{Pt}-\mathrm{Pb} / \mathrm{Poly}(\mathrm{AFCP}-\mathrm{co}-\mathrm{CP})$-BGS catalyst shows better oxidation current for all the alcohols like methanol, ethylene glycol and glycerol, which may be due to the (i) electronic effect, (ii) interaction between metal nanoparticles and Poly(AFCP-co-CP)-BGS composite, (iii) ligand effect, (iv) low onset potential, (v) structural change of platinum in $\mathrm{Pt}-\mathrm{Pb} / \mathrm{Poly}$ (AFCP-co-CP)-BGS catalyst, and (vi) synergic interaction between the metal particles $(\mathrm{Pt}$ and $\mathrm{Pb}$ ) [46]. Table 2 gives the comparative information of catalytic activity of the prepared catalysts and the literature reports, which highlights the novelty and superiority of the prepared composite electrodes.

3.5.1. Mechanism. Hand in hand with the previous literature reports, the enhancement due to the bimetallic system can be explained based on the byproduct formed during the 


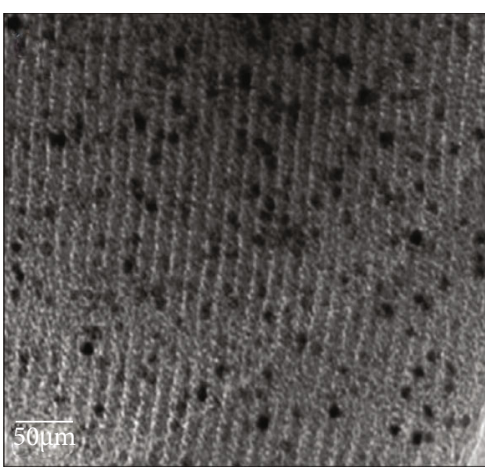

(a)

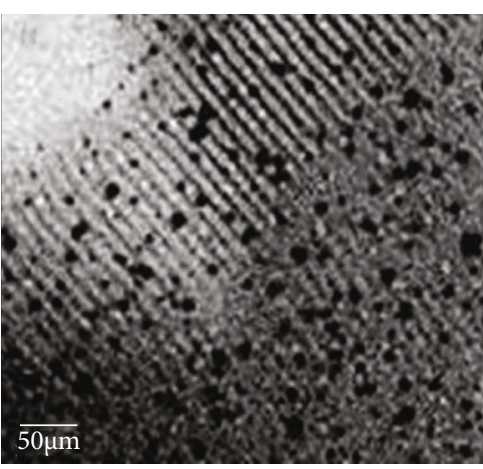

(b)

Figure 4: HRTEM images of (a) Pt/Poly(AFCP-co-CP)-BGS and (b) Pt-Pb/Poly(AFCP-co-CP)-BGS composites.
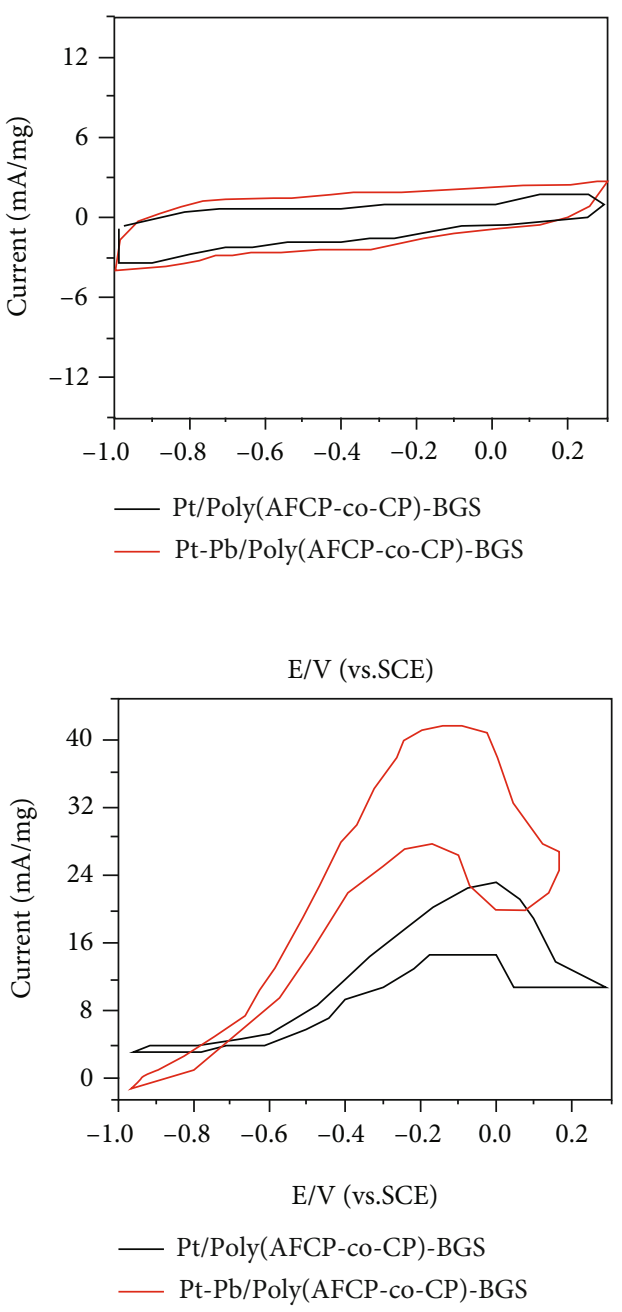
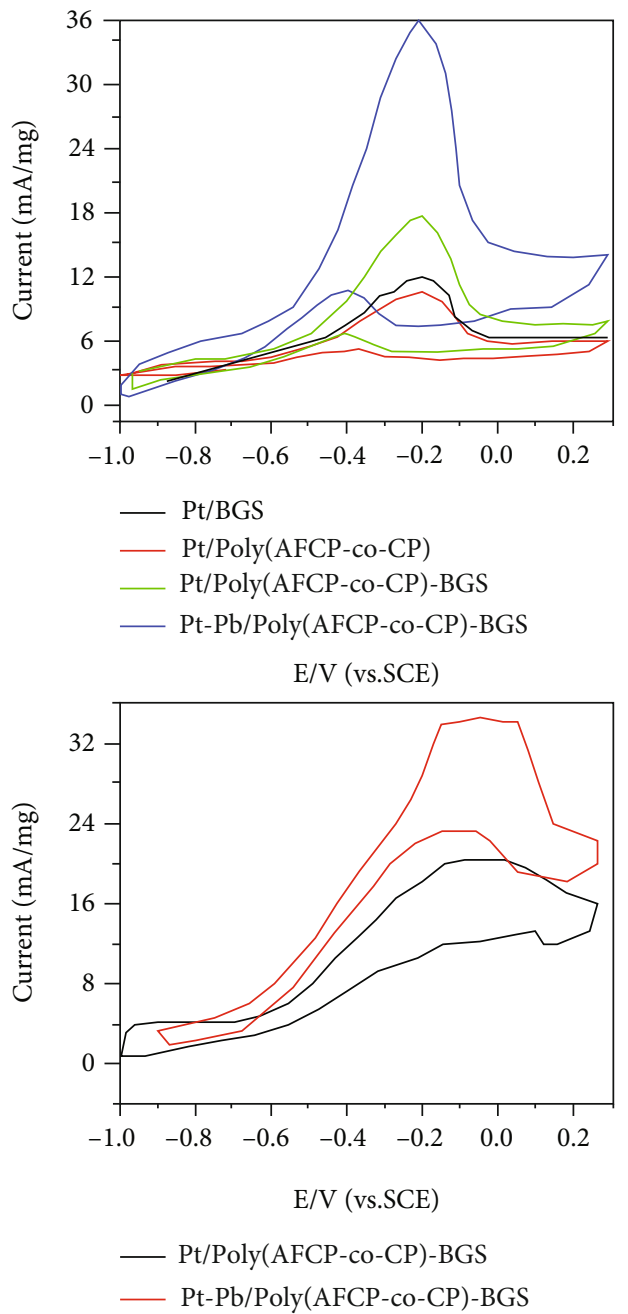

Figure 5: Cyclic voltammograms of Pt- and Pt-Pb-deposited Poly(AFCP-co-CP)-BGS electrodes in (a) $0.5 \mathrm{M} \mathrm{KOH}$, (b) $0.5 \mathrm{M} \mathrm{KOH}+0.5$ $\mathrm{M}$ methanol, (c) $0.5 \mathrm{M} \mathrm{KOH}+0.5 \mathrm{M}$ ethylene glycol, and (d) $0.5 \mathrm{M} \mathrm{KOH}+0.5$ glycerol solution at $50 \mathrm{mV} \mathrm{s}^{-1}$.

electrooxidation of alcohols. According to previous reports [54-56], the formic acid is the major by-product formed during the electrooxidation of methanol, ethylene glycol, and glycerol (Scheme 1).
The obtained formic acid and CO during the electrooxidation of methanol, ethylene glycol and glycerol on the surface of the metal nanoparticles can further undergo oxidation in the presence of oxygen rich species such as $\mathrm{Pt}-\mathrm{OH}$ or $\mathrm{Pb}-\mathrm{OH}$ as 
TABLE 1: Oxidation peak current and onset potential of alcohol on various catalysts.

\begin{tabular}{lcccccc}
\hline \multirow{2}{*}{ Catalysts } & \multicolumn{2}{c}{ Methanol } & \multicolumn{2}{c}{ Ethylene glycol } & \multicolumn{2}{c}{ Glycerol } \\
& $\begin{array}{c}\text { Current } \\
\left(\mathrm{mAmg}^{-1}\right)\end{array}$ & $\begin{array}{c}\text { Onset potential } \\
(\mathrm{V})\end{array}$ & $\begin{array}{c}\text { Current } \\
\left(\mathrm{mAmg}^{-1}\right)\end{array}$ & $\begin{array}{c}\text { Onset potential } \\
(\mathrm{V})\end{array}$ & $\begin{array}{c}\text { Current } \\
\left(\mathrm{mAmg}^{-1}\right)\end{array}$ & $\begin{array}{c}\text { Onset potential } \\
(\mathrm{V})\end{array}$ \\
\hline Pt/BGS & 6.58 & -0.49 & - & - & - & - \\
Pt/Poly(AFCP-co-CP) & 8.62 & -0.54 & - & - & - & - \\
Pt/Poly(AFCP-co-CP)-BGS & 15.14 & -0.62 & 17.08 & -0.83 & 14.63 & -0.90 \\
Pt-Pb/Poly(AFCP-co-CP)-BGS & 36.72 & -0.80 & 38.80 & -0.95 & 30.83 & -0.92 \\
\hline
\end{tabular}

TABLE 2: Comparative studies of the present catalysts with the previous reports, which are carried out under similar experimental conditions.

\begin{tabular}{lccc}
\hline S. no. & Catalysts & Current density $\left(\mathrm{mA} / \mathrm{cm}^{2}\right)$ & Reference \\
\hline 1. & Pt/3D graphene & 1.6 & {$[47]$} \\
2. & Pt/PDDA/graphene & 2.53 & {$[48]$} \\
3. & Pt/3D graphene & 2.5 & {$[49]$} \\
4. & Pt/PDDA/GO & 3.82 & {$[50]$} \\
5. & Pt/CNT/graphene & 11.1 & {$[51]$} \\
6. & PtFe/graphene & 3.55 & {$[52]$} \\
7. & PtSn/graphene & 16.21 & Present work \\
8. & Pt/Poly(AFCP-co-CP)-BGS & 15.14 & Present work \\
9. & Pt-Pb/Poly(AFCP-co-CP)-BGS & 36.72 & \\
\hline
\end{tabular}

given in the following equations (equations (1)-(4)), in accordance with the previous report [49]:

$$
\begin{gathered}
\mathrm{HCOO}-\mathrm{Pt} \stackrel{\mathrm{Pt}-\mathrm{OH}}{\longrightarrow} \mathrm{CO}_{2}+\mathrm{H}_{2} \mathrm{O} \\
\mathrm{HCOO}-\mathrm{Pt} \underset{\mathrm{Pt} / \mathrm{Pb}-\mathrm{OH}}{\longrightarrow} \mathrm{CO}_{2}+\mathrm{H}_{2} \mathrm{O}+2 \mathrm{e}^{-} \\
\mathrm{Pt}+\mathrm{OH}^{-} \longrightarrow \mathrm{Pt}-\mathrm{OH}_{\mathrm{ads}} \stackrel{\mathrm{Pt}-\mathrm{CO}}{\longrightarrow} 2 \mathrm{Pt}+\mathrm{H}_{2} \mathrm{O}+\mathrm{CO}_{2} \\
\mathrm{~Pb}+\mathrm{OH}^{-} \longrightarrow \mathrm{Pb}-\mathrm{OH}_{\mathrm{ads}} \stackrel{\mathrm{Pt}-\mathrm{CO}}{\longrightarrow} \mathrm{Pb}+\mathrm{Pt}+\mathrm{H}_{2} \mathrm{O}+\mathrm{CO}_{2}
\end{gathered}
$$

Here, the rate of oxidation is higher than in the case of bimetallic system (equations (2) and (4)) compared with monometallic system (equations (1) and (2)). This might be due to the easy formation of $\mathrm{Pb}-\mathrm{OH}$ at lower potential and reduction of competition $\mathrm{OH}^{-}$on platinum surface as in the case of bimetallic system. These two processes are expected to enhance the availability of oxygen near to a Pt-CO/Pt$\mathrm{OOCH}$ species and make more number of free active surface area of platinum nanoparticles that are essential for adsorption and oxidation of further alcohol molecules [53].

3.6. Effect of Scan Rates. The diffusion property of alcohol and $\mathrm{OH}^{-1}$ ions during the electrooxidation process was checked for Pt- and Pt-Pb-deposited Poly(AFCP-co-CP)BGS catalysts (Figure 6). From Figure 6, it has been visualized that the anodic oxidation current increases with the increase in the scan rates without changing the onset potential. The insert image in Figure 6 shows a linear relationship for anodic oxidation current obtained from forward CV scans with respect to the square root of different sweep rate, which means that the rate of electrooxidation of methanol, ethylene glycol, and glycerol on Pt/Poly(AFCP-co-CP)-BGS and $\mathrm{Pt}-\mathrm{Pb} / \mathrm{Poly}$ (AFCP-co-CP)-BGS catalysts are controlled by a diffusion process [56].

3.7. Chronoamperometric Analysis. In addition to the above electrochemical analysis, chronoamperometric analysis has also been carried out to test the electrocatalytic activity and stability of $\mathrm{Pt}$ and $\mathrm{Pt}-\mathrm{Pb}$ nanoparticle-deposited Poly(AFCP-co-CP)-BGS catalysts (Figure 7). From chronoamperometric results, it has been noticed that the steady-state oxidation currents have been observed within a few seconds for methanol, ethylene glycol, and glycerol in alkaline medium on both the electrodes. These results indicate that the metal nanoparticle-deposited Poly(AFCP-co-CP)-BGS composite shows good catalytic performance and stability, which are due to the uniform distribution of metal nanoparticles and chemical interaction between metal nanoparticles and Poly(AFCP-co-CP)-BGS composite.

3.8. CO Oxidation on Pt-Pb/Poly(AFCP-co-CP)-BGS and Pt/ Poly (AFCP-co-CP)-BGS Catalysts. Further, CO oxidation has also been carried out in alkaline solution, which can be used to check the catalytic activity and $\mathrm{CO}$ resistance abilities of the prepared lead nanoparticle-doped Pt/Poly(AFCP-co$\mathrm{CP})$-BGS catalyst at room temperature [57-60]. Figure 8 shows the $\mathrm{CO}$ electrooxidation on $\mathrm{Pt}-\mathrm{Pb} / \mathrm{Poly}$ (AFCP-co$\mathrm{CP})$-BGS and Pt/Poly(AFCP-co-CP)-BGS catalysts. The lead nanoparticles doped Pt/Poly(AFCP-co-CP)-BGS catalyst shows enhanced $\mathrm{CO}$ electrooxidation current along with condensed onset potential than that of the Pt/Poly(AFCP-co-CP)BGS catalyst. This observation substantiates that $\mathrm{Pt}-\mathrm{Pb} /$ 


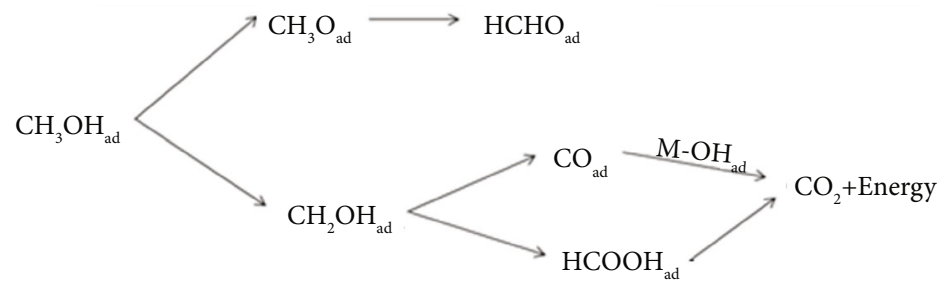

(a)

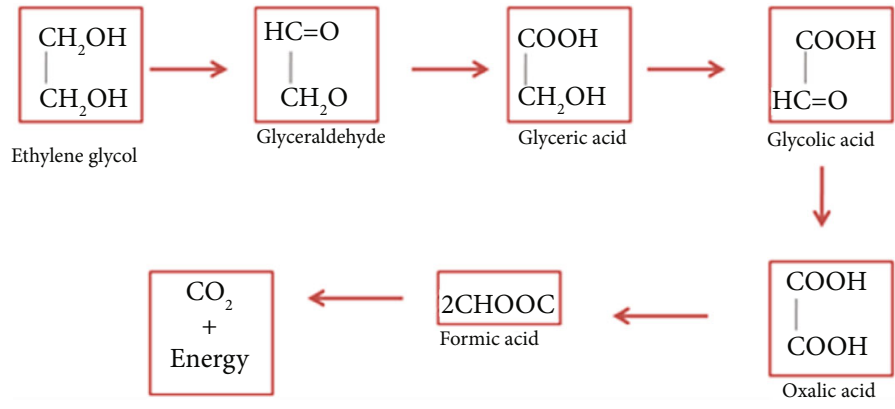

(b)

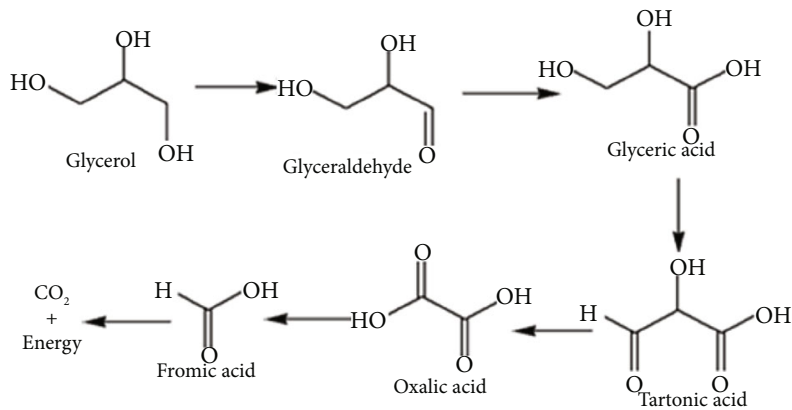

(c)

Scheme 1: Proposed mechanism for the cleavage of (a) methanol, (b) ethylene glycol, and (c) glycerol during the electrooxidation on the catalyst surface.

Poly(AFCP-co-CP)-BGS catalyst has more 'CO' tolerance. This result of carbon monoxide oxidation in alkaline medium also validate that the high catalytic activity and reduced poisonous effect of the $\mathrm{Pt}-\mathrm{Pb} / \mathrm{Poly}(\mathrm{AFCP}-\mathrm{co}-\mathrm{CP})$-BGS catalyst compared to the Pt/Poly(AFCP-co-CP)-BGS catalyst.

3.9. Long-Term Stability and Storage Properties of the Prepared Catalysts. For the practical point of view, longterm stability of the prepared electrode materials is very important. The long-term stability of the prepared Pt/Poly(AFCP-co-CP)-BGS and Pt-Pb/Poly(AFCP-co-CP)-BGS electrodes was examined in $0.5 \mathrm{M}$ Methanol and $0.5 \mathrm{M}$ $\mathrm{NaOH}$ solution (Figure 9) at a scan rate of $50 \mathrm{eV} / \mathrm{s}$. It was observed that the oxidation peak current remains constant with the increase of the scan number at the initial stage. In the case of Pt/Poly(AFCP-co-CP)-BGS catalyst, the oxidation peak current starts decreasing (very small) after 100 numbers of scans.

The peak current density of the 500th scan is about 98.2\% for Pt/Poly(AFCP-co-CP)-BGS catalyst than that of the first scan. In general, the small loss of the catalytic activity after successive number of scans may result from the con- sumption of methanol during the CV scan. It also may be due to poisoning effect and the structure change of the platinum nanoparticles as a consequence of the perturbation of the potentials during the scanning in aqueous solutions, particularly in the existence of methanol or any other organic fuel compounds $[45,61,62]$. Another characteristic might be due to the dispersion process happening between the surface of the electrode and the bulk solution.

With magnification of scan number, methanol disseminates gradually from the bulk solution to the surface of the electrode materials. In Pt-Pb/Poly(AFCP-co-CP)-BGS electrode, a sufficient enhancement was noticed, and the oxidation peak current decreased (very small) only after 250 numbers of scans. In Pt/Poly(AFCP-co-CP)-BGS, still, the electrode gets accumulated by COads poison, and hence, the anodic oxidation current decreases after the 100th scan itself showing a less stability. After the long-term electrocatalytic oxidation experiments, the $\mathrm{Pt}-\mathrm{Pb} / \mathrm{Poly}(\mathrm{AFCP}-\mathrm{co}-$ $\mathrm{CP})$-BGS and Pt/Poly(AFCP-co-CP)-BGS electrodes were stored in double distilled water for a week and electrooxidation of methanol was carried out. The excellent catalytic activities for the alcohol oxidations are still observed, which 


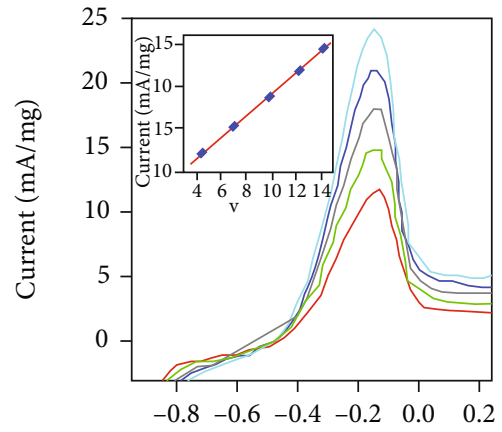

E/V (vs.SCE)

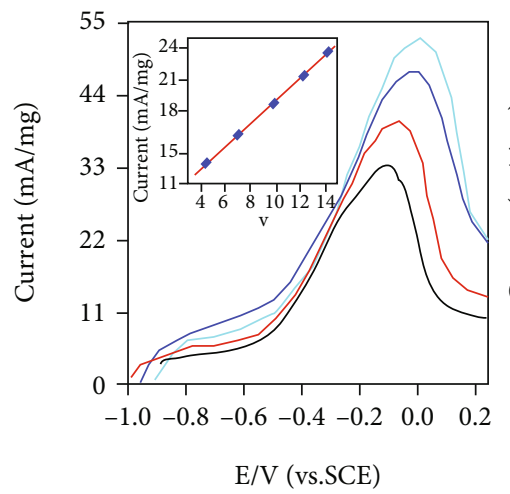

$\begin{array}{rr}20 \mathrm{mv} / \mathrm{s} & -150 \mathrm{mv} / \mathrm{s} \\ -50 \mathrm{mv} / \mathrm{s} & -200 \mathrm{mv} / \mathrm{s} \\ - & 100 \mathrm{mv} / \mathrm{s}\end{array}$
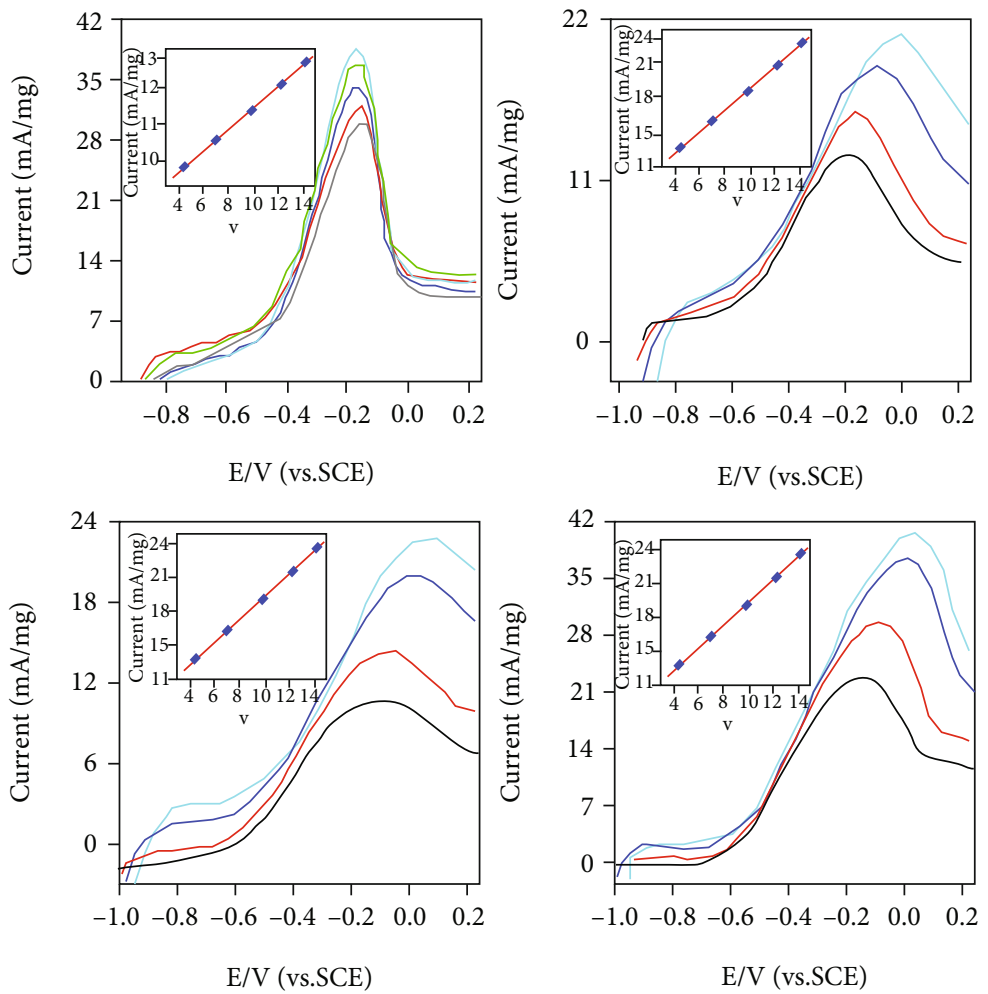

Figure 6: Effect of scan rate on Pt- and Pt-Pb-deposited Poly(AFCP-co-CP)-BGS catalysts for (i) $0.5 \mathrm{M}$ methanol (a, b), (ii) $0.5 \mathrm{M}$ ethylene glycol (c, d), and (iii) $0.5 \mathrm{M}$ glycerol (e, f) in $0.5 \mathrm{M} \mathrm{KOH}$ solution. The inset graphs show the dependence of the anodic oxidation current with respect to the square root of scan rates.
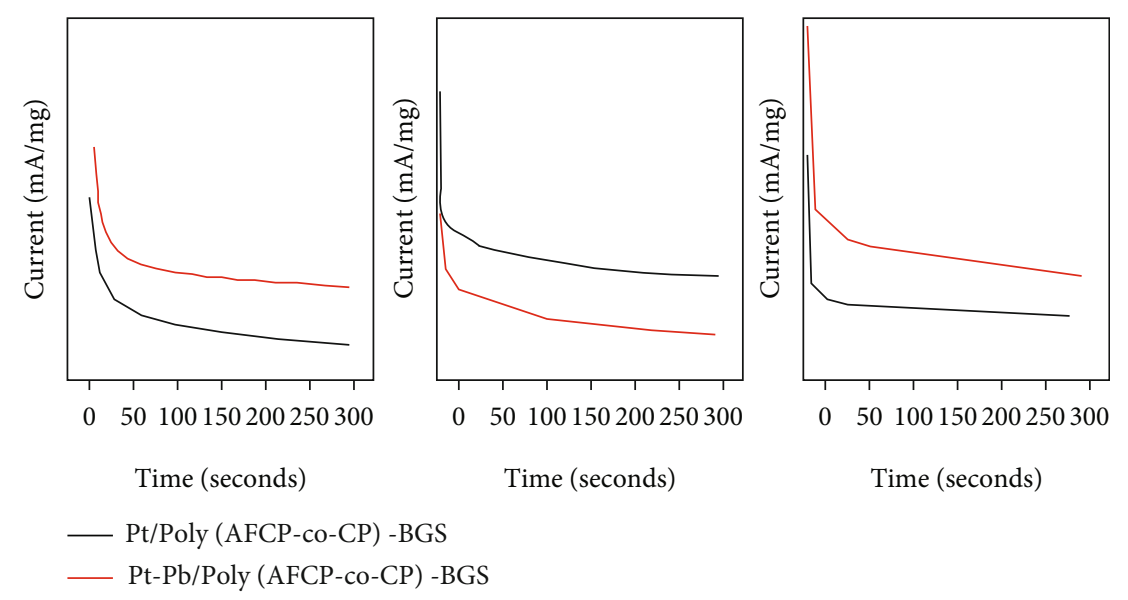

FIgure 7: Chronoamperometric curves of Pt/Poly(AFCP-co-CP)-BGS and Pt-Pb/Poly(AFCP-co-CP)-BGS catalysts for (a) $0.5 \mathrm{M}$ methanol, (b) $0.5 \mathrm{M}$ ethylene glycol, and (c) $0.5 \mathrm{M}$ glycerol in $0.5 \mathrm{M} \mathrm{KOH}$ solution. 


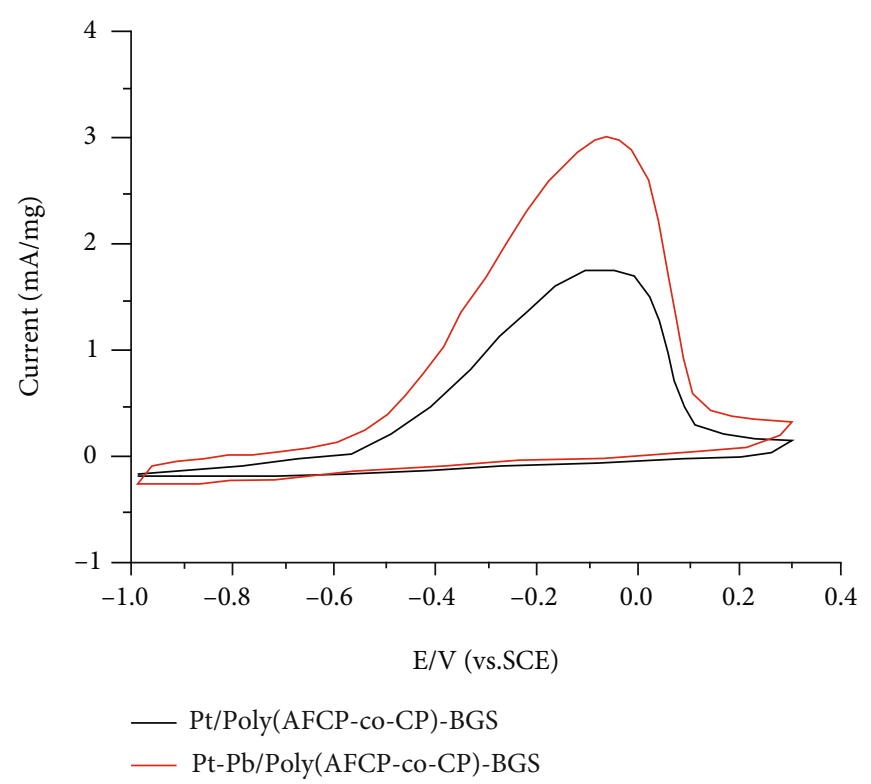

Figure 8: The electrooxidation of $\mathrm{CO}$ on the newly prepared Pt/Poly(AFCP-co-CP)-BGS and Pt-Pb/Poly(AFCP-co-CP)-BGS catalysts.

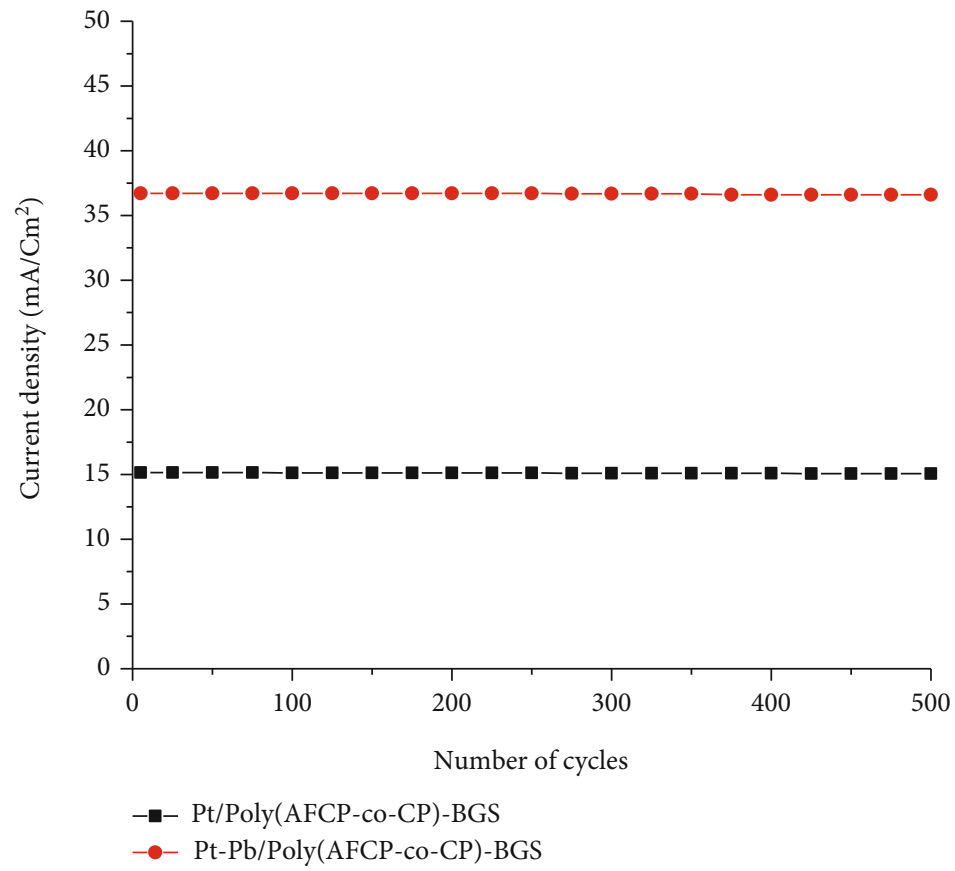

FIGURE 9: Long-term stability of the prepared Pt/Poly(AFCP-co-CP)-BGS and Pt-Pb/Poly(AFCP-co-CP)-BGS electrodes in $0.5 \mathrm{M}$ methanol and $0.5 \mathrm{M} \mathrm{NaOH}$ solution at a scan rate of $50 \mathrm{eV} / \mathrm{s}$.

indicate that the Pt/Poly(AFCP-co-CP)-BGS and $\mathrm{Pt}-\mathrm{Pb} /$ Poly(AFCP-co-CP)-BGS composites prepared in the present experiment have good long-term stability and storage properties.

3.10. Direct Alkaline Alcohol Fuel Cell Studies. The single stack direct alkaline alcohol test fuel cell has been constructed to find out polarization and power density curve using $\mathrm{Pt}-\mathrm{Pb} / \mathrm{Poly}(\mathrm{AFCP}-\mathrm{co}-\mathrm{CP})$-BGS catalyst as an anode in accordance with our previous report [61]. According to our previous studies [45, 61-63], polarization and power density have been measured at an optimum fuel concentration of $2.0 \mathrm{M}$ in $1.0 \mathrm{M} \mathrm{NaOH}$ and at an optimum temperature of $70^{\circ} \mathrm{C}$ and their results are shown in Figure 10. The experimental results concluded that the direct alkaline ethylene glycol fuel cell has showed the maximum power density of $190 \mathrm{~mW} \mathrm{~cm}^{-2}$ at $70^{\circ} \mathrm{C}$ compared to methanol and glycerol, which has good agreement with cyclic voltammetric results. 


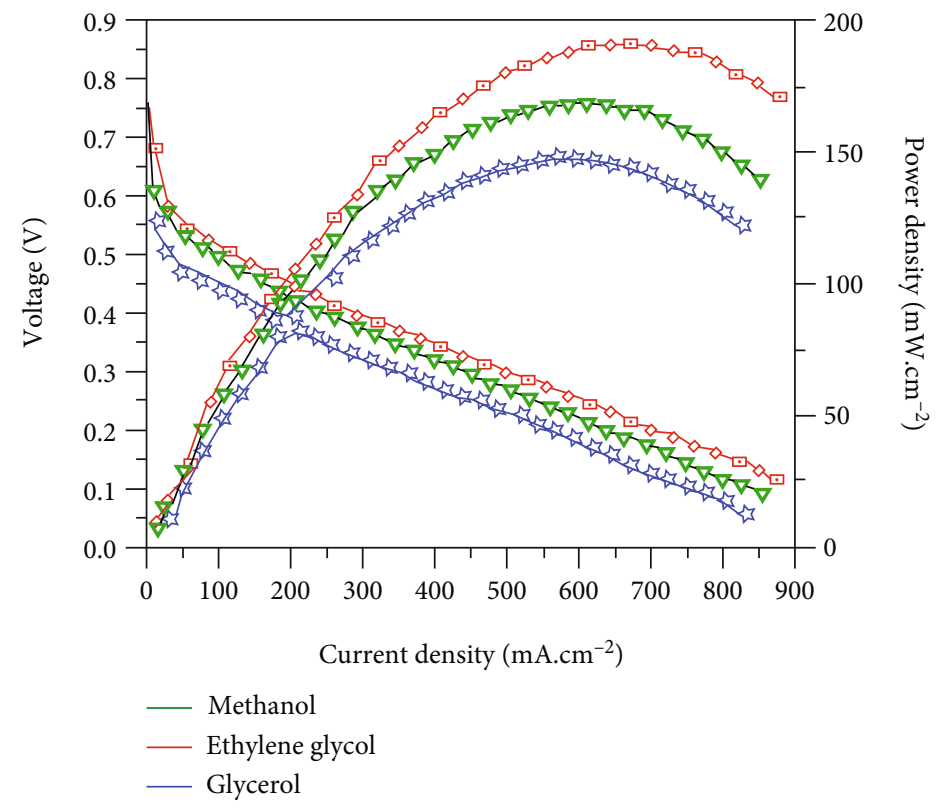

Figure 10: Polarization and current density curves of single stack fuel cell using Pt-Pb/Poly(AFCP-co-CP)-BGS as electrode material in (a) $1.0 \mathrm{M} \mathrm{NaOH}+2.0 \mathrm{M} \mathrm{CH}_{3} \mathrm{OH}$, (b) $1.0 \mathrm{M} \mathrm{NaOH}+2.0 \mathrm{M}$ ethylene glycol, and (c) $1.0 \mathrm{M} \mathrm{NaOH}+2.0 \mathrm{M}$ glycerol at $70^{\circ} \mathrm{C}$.

Hence, the prepared Pt-Pb/Poly(AFCP-co-CP)-BGS catalyst can be used to construct the alkaline alcohol fuel battery for commercial real-time practical applications.

\section{Conclusion}

Platinum-lead bimetallic nanoparticles have been loaded on Poly(AFCP-co-CP)-BGS composite through codeposition method to promote both electrooxidation of alcohol and $\mathrm{CO}$ oxidation, which are essential processes for fuel cell applications. Various characterizations have been carried out to determine the catalytic activity, particle size, shape, uniform distribution, and dispersion over the catalyst support. $\mathrm{Pt}-\mathrm{Pb}$ / Poly(AFCP-co-CP)-BGS catalyst has shown enhanced oxidation current and lower onset potential for methanol, ethylene glycol, and glycerol oxidation in alkaline medium compared to Pt/Poly(AFCP-co-CP)-BGS catalyst. Moreover, Pt/Poly(AFCP-co-CP)-BGS catalyst exhibits higher oxidation current for methanol compared with Pt/Poly(AFCP-co-CP) and Pt/ BGS catalyst. It has been concluded from these results that the prepared Poly(AFCP-co-CP)-BGS support has been identified as a promising potent for electrocatalyst. Further, lead nanoparticle-deposited Pt/Poly(AFCP-co-CP)-BGS catalyst has been shown to improve $\mathrm{CO}$ oxidation and lower onset potential compared to $\mathrm{Pt} / \mathrm{Poly}(\mathrm{AFCP}-\mathrm{co}-\mathrm{CP})-\mathrm{BGS}$ catalyst. Hence, the above studies conclude that not only the Poly(AFCP-co-CP)-BGS supporting material, but the introduction of lead also shows significant oxidation current for both alcohol and CO oxidation at a lower onset potential itself and thus reduces more $\mathrm{CO}$ catalytic poison effect.

\section{Data Availability}

All the data analyzed or used during this study are included within this article.

\section{Conflicts of Interest}

The authors declare that they have no conflicts of interest.

\section{References}

[1] S. Sen Gupta and J. Datta, "Electrode kinetics of ethanol oxidation on novel $\mathrm{CuNi}$ alloy supported catalysts synthesized from PTFE suspension," Journal of Power Sources, vol. 145, no. 2, pp. 124-132, 2005.

[2] Y. Xiong, Q. L. Liu, A. M. Zhu, S. M. Huang, and Q. H. Zeng, "Performance of organic-inorganic hybrid anion-exchange membranes for alkaline direct methanol fuel cells," Journal of Power Sources, vol. 186, no. 2, pp. 328-333, 2009.

[3] Y. Liu, H. Yang, X. Y. Li, and L. Q. Mao, "Pt nanoparticles supported on monodisperse carbon spheres for methanol oxidation in alkaline media," Materials Letters, vol. 106, pp. 287289, 2013.

[4] C. W. Xu, L. Q. Cheng, P. K. Shen, and Y. L. Liu, "Methanol and ethanol electrooxidation on Pt and Pd supported on carbon microspheres in alkaline media," Electrochemistry Communications, vol. 9, no. 5, pp. 997-1001, 2007.

[5] Y. Hu, A. Zhu, C. Zhang, Q. Zhang, and Q. Liu, "Microwaveassisted synthesis of double-shell $\mathrm{PtRu} / \mathrm{TiO}_{2}$ catalyst towards methanol electro-oxidation," International Journal of Hydrogen Energy, vol. 40, no. 45, pp. 15652-15662, 2015.

[6] F. Ren, C. Zhai, M. Zhu et al., "Facile synthesis of PtAu nanoparticles supported on polydopamine reduced and modified graphene oxide as a highly active catalyst for methanol oxidation," Electrochimica Acta, vol. 153, pp. 175-183, 2015.

[7] G. Zhang, C. Huang, R. Qin et al., "Uniform Pd-Pt alloy nanoparticles supported on graphite nanoplatelets with high electrocatalytic activity towards methanol oxidation," Journal of Materials Chemistry A, vol. 3, no. 9, pp. 5204-5211, 2015.

[8] Y. Zhang, Y. Liu, W. Liu, X. Li, and L. Mao, "Synthesis of honeycomb-like mesoporous nitrogen-doped carbon 
nanospheres as Pt catalyst supports for methanol oxidation in alkaline media," Applied Surface Science, vol. 407, pp. 64-71, 2017.

[9] P. K. Shen, Z. Yan, H. Meng et al., "Synthesis of Pd on porous hollow carbon spheres as an electrocatalyst for alcohol electrooxidation," RSC Advances, vol. 1, no. 2, pp. 191-198, 2011.

[10] C. Chen, Y. Li, and S. Liu, "Fabrication of macroporous platinum using monodisperse silica nanoparticle template and its application in methanol catalytic oxidation," Journal of Electroanalytical Chemistry, vol. 632, no. 1-2, pp. 14-19, 2009.

[11] V. Selvaraj, M. Alagar, and I. Hamerton, "Nanocatalysts impregnated polythiophene electrodes for the electrooxidation of formic acid," Applied Catalysis B: Environmental, vol. 73, no. 1-2, pp. 172-179, 2007.

[12] H. Liao, Z. Qiu, Q. Wan, Z. Wang, Y. Liu, and N. Yang, "Universal electrode Interface for Electrocatalytic oxidation of liquid fuels," ACS Applied Materials \& Interfaces, vol. 6, no. 20, pp. 18055-18062, 2014.

[13] M. Liu, C. Peng, W. Yang et al., "Pd nanoparticles supported on three-dimensional graphene aerogels as highly efficient catalysts for methanol electrooxidation," Electrochimica Acta, vol. 178, pp. 838-846, 2015.

[14] P. Song, L. Zhu, X. Bo, A. Wang, G. Wang, and L. Guo, "Pt nanoparticles incorporated into phosphorus-doped ordered mesoporous carbons: enhanced catalytic activity for methanol electrooxidation," Electrochimica Acta, vol. 127, pp. 307-314, 2014.

[15] A. H. Lu, T. Sun, W. C. Li et al., "Synthesis of Discrete and dispersible hollow carbon nanospheres with high uniformity by Using Confined Nanospace pyrolysis," Angewandte Chemie, International Edition, vol. 50, no. 49, pp. 11765-11768, 2011.

[16] K. Kalpana and V. Selvaraj, "Development of ZnS/SnS/A-FA nanorods at ambient temperature: binary catalyst for the removal of Congo red dye and pathogenic bacteria from wastewater," Journal of Industrial and Engineering Chemistry, vol. 41, pp. 105-113, 2016.

[17] S. Durairaj and S. Vaithilingam, "Hydrothermal assisted synthesis of zeolite based nickel deposited poly(pyrrole-co-fluoro aniline)/CuS catalyst for methanol and sulphur fuel cell applications," Journal of Electroanalytical Chemistry, vol. 787, pp. 55-65, 2017.

[18] C. W. Zhang, L. B. Xu, N. N. Shan, T. T. Sun, J. F. Chen, and Y. S. Yan, "Enhanced electrocatalytic activity and durability of Pt particles supported on ordered mesoporous carbon spheres," ACS Catalysis, vol. 4, no. 6, pp. 1926-1930, 2014.

[19] S. Zhang, L. Chen, S. Zhou, D. Zhao, and L. Wu, "Facile synthesis of Hierarchically Ordered porous carbon viain SituSelf-Assembly of colloidal polymer and Silica Spheres and its use as a catalyst support," Chemistry of Materials, vol. 22, no. 11, pp. 3433-3440, 2010.

[20] H. W. Liang, X. Zhuang, S. Bruller, X. Feng, and K. Mullen, "Hierarchically porous carbons with optimized nitrogen doping as highly active electrocatalysts for oxygen reduction," Nature Communications, vol. 5, no. 1, p. 4973, 2014.

[21] Y. Liu, Y. M. Zhang, C. P. Zhai, X. Y. Li, and L. Q. Mao, "Nitrogen-doped porous carbons supported Pt nanoparticles for methanol oxidation in alkaline medium," Materials Letters, vol. 166, pp. 16-18, 2016.

[22] A. Navaee, A. Salimi, S. Soltanian, and P. Servati, "Facile onepot synthesis of platinum nanoparticles decorated nitrogengraphene with high electrocatalytic performance for oxygen reduction and anodic fuels oxidation," Journal of Power Sources, vol. 277, pp. 268-276, 2015.

[23] S. J. J. Jiang, L. Zhu, Y. W. Ma et al., "Direct immobilization of $\mathrm{Pt}-\mathrm{Ru}$ alloy nanoparticles on nitrogen-dopedcarbon nanotubes with superior electrocatalytic performance," Journal of Power Sources, vol. 195, pp. 7578-7582, 2010.

[24] Y. Shao, J. Sui, G. Yin, and Y. Gao, "Nitrogen-doped carbon nanostructures and their composites as catalytic materials for proton exchange membrane fuel cell," Applied Catalysis B, Environmental, vol. 79, no. 1, pp. 89-99, 2008.

[25] L. M. Zhang, Z. B. Wang, J. J. Zhang, X. L. Sui, L. Zhao, and D. M. Gu, "Honeycomb-like mesoporous nitrogen-doped carbon supported Pt catalyst for methanol electrooxidation," Carbon, vol. 93, pp. 1050-1058, 2015.

[26] V. Selvaraj and T. R. Raghavarshini, "Development of highperformance hybrid sustainable bio-composites from biobased carbon reinforcement and cardanol-benzoxazine matrix," Polymer Bulletin, vol. 78, no. 8, pp. 4129-4148, 2021.

[27] V. Selvaraj, T. R. Raghavarshini, and M. Alagar, "Design and development of bio-carbon reinforced hetero structured biophenolics polybenzoxazine-epoxy hybrid composites for high performance applications," Journal of Polymer Research, vol. 28, no. 5, 2021.

[28] V. Selvaraj and T. R. Raghavarshini, "Building up of Prosopis juliflora carbon incorporated cardanol based polybenzoxazine composites with intensification of mechanical and corrosion resistance properties for adaptable applications," Polymer Bulletin, vol. 77, no. 12, pp. 6449-6466, 2020.

[29] X. Huang, B. Dai, Y. Ren, X. Jing, and P. Zhu, "Preparation and study of electromagnetic interference shielding materials comprised of Ni-Co coated on web-like biocarbon nanofibers via electroless deposition," Journal of Nanomaterials, vol. 2015, Article ID 320306, 7 pages, 2015.

[30] P. Bijesh, V. Selvaraj, and V. Andal, "A review on synthesis and applications of nano metal oxide/porous carbon composite," Materials Today: Proceedings, 2021.

[31] E. G. Ertane, A. Dorner-Reisel, O. Baran, T. Welzel, V. Matner, and S. Svoboda, "Processing and wear behaviour of 3D printed PLA reinforced with biogenic carbon," Advances in Tribology, vol. 2018, Article ID 1763182, 11 pages, 2018.

[32] K. Arunkumar and V. Selvaraj, "Development of livestock poultry waste based $\mathrm{Ni}-\mathrm{Co} / \mathrm{S}$ green nanocomposite catalysts: a facile one-pot in situ solvothermal method for alkaline methanol oxidation and super capacitor applications," Ionics, vol. 27, no. 8, pp. 3587-3603, 2021.

[33] S. Vaithilingam and T. M. Ramanujam, "Development of rice straw black liquor based porous carbon-poly (aniline-comethoxy aniline) as supporting for electrochemical performances of alcohol oxidations," Ionics, vol. 24, no. 12, pp. 3923-3935, 2018.

[34] R. Abdel-Karim, M. Ramadan, and S. M. El-Raghy, "Morphology and electrochemical characterization of electrodeposited nanocrystalline Ni-Co electrodes for methanol fuel cells," Journal of Nanomaterials, vol. 2018, Article ID 9870732, 13 pages, 2018.

[35] I. M. Al-Akraa, Y. M. Asal, and A. M. Mohammad, "Facile synthesis of a tailored-designed $\mathrm{Au} / \mathrm{Pt}$ nanoanode for enhanced formic acid, methanol, and ethylene glycol electrooxidation," Journal of Nanomaterials, vol. 2019, Article ID 2784708, 9 pages, 2019.

[36] T. Xia, H. Shen, G. Chang et al., "Facile and rapid synthesis of ultrafine PtPd bimetallic nanoparticles and their high 
performance toward methanol electro-oxidation," Journal of Nanomaterials, vol. 2014, Article ID 496249, 7 pages, 2014.

[37] S. Chao, Q. Cui, Z. Bai, K. Wang, and L. Yang, "Template-free synthesis of hierarchical peanut-like Co and $\mathrm{N}$ codoped porous carbon with highly efficient catalytic activity for oxygen reduction reaction," Electrochimica Acta, vol. 177, pp. 79-85, 2015.

[38] M. Sevilla, L. Yu, T. Fellinger, A. Fuertes, and M. M. Titirici, "Polypyrrole-derived mesoporous nitrogen-doped carbons with intrinsic catalytic activity in the oxygen reduction reaction," RSC Advances, vol. 3, no. 25, pp. 9904-9910, 2013.

[39] G. Wang, Y. Sun, D. Li et al., "Controlled Synthesis of N-doped carbon nanospheres with tailored Mesopores through SelfAssembly of colloidal silica," Angewandte Chemie, International Edition, vol. 54, no. 50, pp. 15191-15196, 2015.

[40] K. Gong, F. Du, Z. Xia, M. Durstock, and L. Dai, "Nitrogendoped carbon Nanotube Arrays with high electrocatalytic activity for oxygen reduction," Science, vol. 323, no. 5915, pp. 760-764, 2009.

[41] Y. Xue, B. Wu, L. Jiang et al., "Low temperature growth of highly nitrogen-doped single crystal Graphene arrays by chemical vapor deposition," Journal of the American Chemical Society, vol. 134, no. 27, pp. 11060-11063, 2012.

[42] K. Kim, M. P. Kim, and W.-G. Lee, "Preparation and evaluation of mesoporous carbon derived from waste materials for hybrid-type Li-air batteries," New Journal of Chemistry, vol. 41, no. 17, pp. 8864-8869, 2017.

[43] K. Krishnadevi and V. Selvaraj, "Development of halogen-free flame retardant phosphazene and rice husk ash incorporated benzoxazine blended epoxy composites for microelectronic applications," New Journal of Chemistry, vol. 39, no. 8, pp. 6555-6567, 2015.

[44] K. Krishnadevi, V. Selvaraj, and D. Prasanna, "Thermal, mechanical and antibacterial properties of cyclophosphazene incorporated benzoxazine blended bismaleimide composites," RSC Advances, vol. 5, no. 2, pp. 913-921, 2015.

[45] D. Prasanna and V. Selvaraj, "Development of ternary hexafluoroisopropylidenedianiline/cyclophosphazene/benzidinedisulfonic acid- carbon nanotubes (HFPA/CP/BZD-CNT) composite as a catalyst support for high performance alcohol fuel cell applications," Electrochimica Acta, vol. 190, pp. 668677, 2016.

[46] M. Gong, F. Li, Z. Yao et al., "Highly active and durable platinum-lead bimetallic alloy nanoflowers for formic acid electrooxidation," Nanoscale, vol. 7, no. 11, pp. 4894-4899, 2015.

[47] X. D. ThandavarayanMaiyalagan, P. Chen, and X. Wang, "Electrodeposited Pt on three-dimensional interconnected grapheneasa free-standing electrode for fuel cell application," Journal of Materials Chemistry, vol. 22, pp. 5286-5290, 2012.

[48] J.-D. Qiu, G.-C. Wang, R.-P. Liang, X.-H. Xia, and H. W. Yu, "Controllable deposition of platinum nanoparticles on graphene as an electrocatalyst for direct methanol fuel cells," Journal of Physical Chemistry C, vol. 115, no. 31, pp. 15639-15645, 2011.

[49] H. Qiu, X. Dong, B. Sana et al., "Ferritin-templated synthesis and self-assembly of Pt Nanoparticles on a monolithic porous graphene network for Electrocatalysis in Fuel cells," ACS Applied Materials \& Interfaces, vol. 5, no. 3, pp. 782-787, 2013.

[50] J. Y. Park and S. Kim, "Preparation and electroactivity of polymer-functionalized graphene oxide- supported platinum nanoparticles catalysts," International Journal of Hydrogen Energy, vol. 38, no. 14, pp. 6275-6282, 2013.
[51] J.-Y. Jhan, Y.-W. Huang, C.-H. Hsu, H. Teng, D. Kuo, and P.L. Kuo, "Three-dimensional network of graphene grown with carbon nanotubes as carbon support for fuel cells," Energy, vol. 53, pp. 282-287, 2013.

[52] X. Y. BaominLuo, J. Chen, S. Xu, and Q. Xue, "PtFe nanotubes/ graphene hybrid: facile synthesisand its electrochemical properties," International Journal of Hydrogen, vol. 38, pp. 1301113016, 2013.

[53] F. Han, X. Wang, J. Lian, and Y. Wang, "The effect of Sn content on the electrocatalytic properties of Pt-Sn nanoparticles dispersed on graphene nanosheets for the methanol oxidation reaction," Carbon, vol. 50, no. 15, pp. 5498-5504, 2012.

[54] R. Nagao, D. A. Cantane, F. H. B. Lima, and H. Varela, "The dual pathway in action: decoupling parallel routes for $\mathrm{CO}_{2}$ production during the oscillatory electro-oxidation of methanol," Physical Chemistry Chemical Physics, vol. 14, no. 23, pp. 8294-8298, 2012.

[55] H. Yue, Y. Zhao, X. Ma, and J. Gong, "Ethylene glycol: properties, synthesis, and applications," Chemical Society Reviews, vol. 41, no. 11, pp. 4218-4244, 2012.

[56] Z. Zhang, L. Xin, J. Qi, Z. Wang, and W. Li, "Selective electroconversion of glycerol to glycolate on carbon nanotube supported gold catalyst," Green Chemistry, vol. 14, no. 8, pp. 2150-2152, 2012.

[57] E. A. Baranova, M. A. Padilla, B. Halevi, T. Amir, K. Artyushkova, and P. Atanassov, "Electrooxidation of ethanol on PtSn nanoparticles in alkaline solution: correlation between structure and catalytic properties," Electrochimica Acta, vol. 80, pp. 377-382, 2012.

[58] E. Antolini and E. R. Gonzalez, "The electro-oxidation of carbon monoxide, hydrogen/carbon monoxide and methanol in acid medium on Pt-Sn catalysts for low-temperature fuel cells: a comparative review of the effect of Pt-Sn structural characteristics," Electrochimica Acta, vol. 56, no. 1, pp. 1-14, 2010.

[59] Y. Sun, C. Du, M. An et al., "Boron-doped graphene as promising support for platinum catalyst with superior activity towards the methanol electrooxidation reaction," Journal of Power Sources, vol. 300, pp. 245-253, 2015.

[60] J. Sun, J. Shi, J. Xu, X. Chen, Z. Zhang, and Z. Peng, "Enhanced methanol electro-oxidation and oxygen reduction reaction performance of ultrafine nanoporous platinum-copper alloy: Experiment and density functional theory calculation," Journal of Power Sources, vol. 279, pp. 334-344, 2015.

[61] P. Dakshinamoorthy and S. Vaithilingam, "Platinum-copper doped poly(sulfonyldiphenol/cyclophosphazene/benzidine)graphene oxide composite as an electrode material for single stack direct alcohol alkaline fuel cells," RSC Advances, vol. 7, no. 56, pp. 34922-34932, 2017.

[62] D. Prasanna and V. Selvaraj, "Cyclophosphazene based conductive polymer-carbon nanotube composite as novel supporting material for methanol fuel cell applications," Journal of Colloid and Interface Science, vol. 472, no. 15, pp. 116-125, 2016.

[63] D. Saranya and V. Selvaraj, "Double metal oxide based nickel hybrid nanocatalyst for electrooxidation and alkaline fuel cell device fabrication," International Journal of Hydrogen Energy, vol. 43, no. 29, pp. 13450-13461, 2018. 